REVISTA PORTUGUESA DE PSICOLOGA

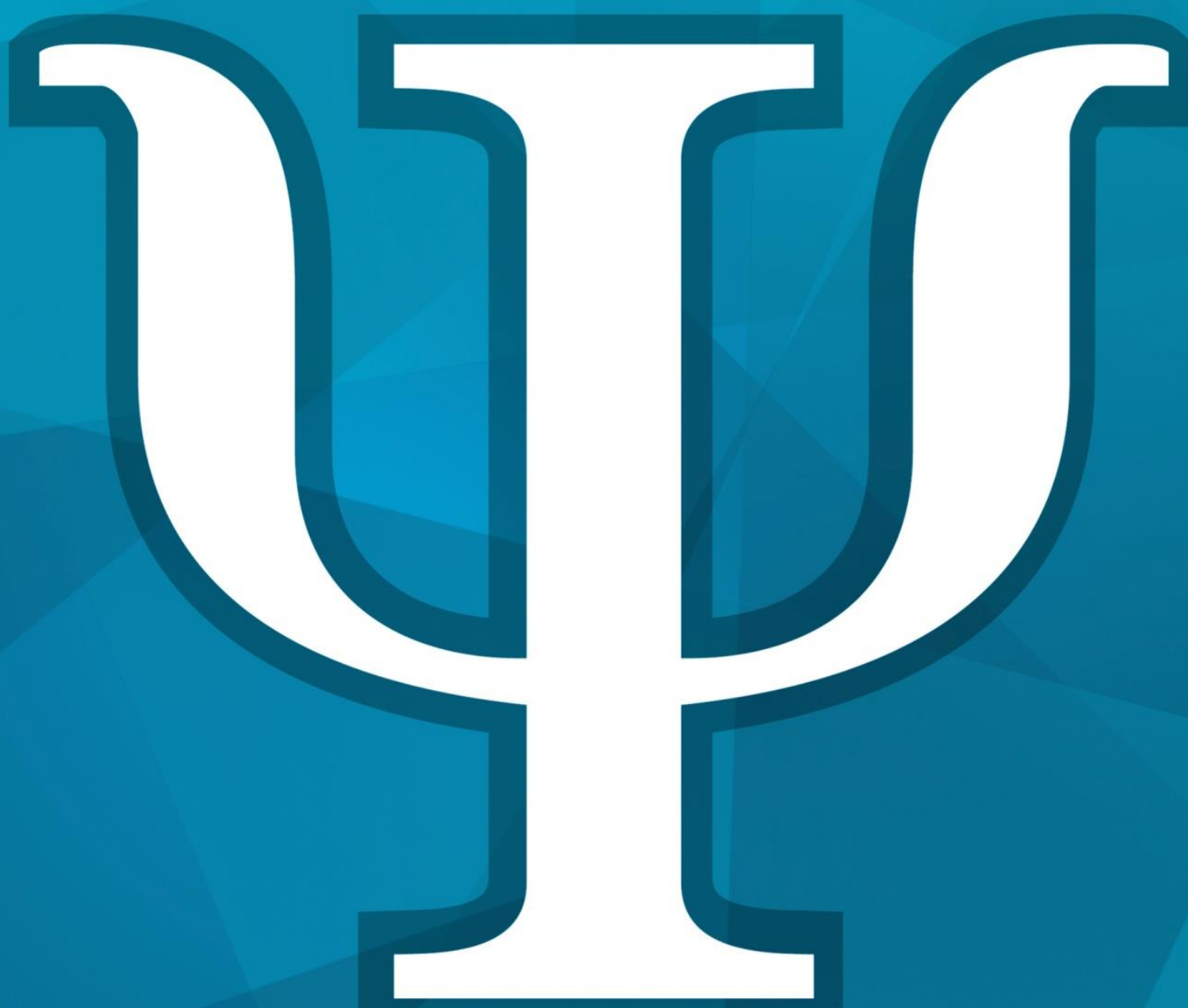




\section{Conselho Editorial / Editorial Board}

\section{Editor:}

João Manuel Moreira

Faculdade de Psicologia, Universidade de Lisboa

\section{Conselho Editorial / Editorial Board:}

Adelina Lopes da Silva

Faculdade de Psicologia, Universidade de Lisboa

Alexandra Reis

Faculdade de Ciências Humanas e Sociais, Universidade do Algarve

Amâncio da Costa Pinto

Faculdade de Psicologia e CE, Universidade do Porto

Ana Margarida Veiga Simão

Faculdade de Psicologia, Universidade de Lisboa

Bárbara Figueiredo

Escola de Psicologia, Universidade do Minho

Danilo Silva

Faculdade de Psicologia, Universidade de Lisboa

Félix Neto

Faculdade de Psicologia e CE, Universidade do Porto

Helio Carpinteiro

Universidade Complutense de Madrid

Isabel Sá

Faculdade de Psicologia, Universidade de Lisboa

Isabel Soares

Escola de Psicologia, Universidade do Minho

Jean Guichard

Conservatoire National des Arts et Métiers

José Frederico Marques

Faculdade de Psicologia, Universidade de Lisboa

José H. Ferreira-Marques

Faculdade de Psicologia, Universidade de Lisboa

José Keating

Escola de Psicologia, Universidade do Minho

José Tomás da Silva

Faculdade de Psicologia e CE, Universidade de Coimbra

Leonel Garcia-Marques

Faculdade de Psicologia, Universidade de Lisboa

Leonor Cardoso

Faculdade de Psicologia e CE, Universidade de Coimbra

Luísa Barros

Faculdade de Psicologia, Universidade de Lisboa

Luísa Morgado

Faculdade de Psicologia e CE, Universidade de Coimbra

Manuel Rafael

Faculdade de Psicologia, Universidade de Lisboa
Maria do Céu Taveira

Escola de Psicologia, Universidade do Minho

Maria Eduarda Duarte

Faculdade de Psicologia, Universidade de Lisboa

Maria José Chambel

Faculdade de Psicologia, Universidade de Lisboa

Mário Ferreira

Faculdade de Psicologia, Universidade de Lisboa

Mário Simões

Faculdade de Psicologia e CE, Universidade de Coimbra

Mark Savickas

Northeast Ohio Medical University

Paulo Ventura

Faculdade de Psicologia, Universidade de Lisboa

Pedro B. Albuquerque

Escola de Psicologia, Universidade do Minho

Rocío Fernandez-Ballesteros

Universidad Autónoma de Madrid

Rosário Lima

Faculdade de Psicologia, Universidade de Lisboa

Salomé Vieira Santos

Faculdade de Psicologia, Universidade de Lisboa

São Luís Castro

Faculdade de Psicologia e CE, Universidade do Porto

\section{Assistente Editorial / Editorial Assistant:}

Rita Monteiro

Editores e Directores Eméritos / Emeriti Editors and Directors:

Henrique Barahona Fernandes

Director, 1967-1991

Agostinho Pereira

Editor, 1967-1969

José Luiz Simões da Fonseca Editor, 1969-1971

José H. Ferreira-Marques

1992-2001

Danilo Silva

2002-2005

Manuel Rafael

2006-2011

\section{Instruções aos autores:}

https://sites.google.com/site/revistaportuguesadepsicologia /instrucoes-aos-autores

ISSN 2183-3699 (versão electrónica / electronic version) ISSN 0872-0304 (versão impressa / print version) 


\title{
A perceção da escola e do trabalho em crianças de jardim de infância e suas mães
}

\author{
Márcia Gouveia \\ Departamento de Psicologia, Universidade de Évora \\ Paulo Cardoso \\ Departamento de Psicologia, Universidade de Évora
}

\section{RESUMO}

A presente investigação analisa a perceção da escola e do trabalho em crianças de jardim de infância e suas mães. Também se estudam diferenças de resultados em função da proveniência urbana ou rural dos participantes. A amostra foi constituída por 23 crianças (dos 3 aos 6 anos), 12 do sexo feminino e 11 do sexo masculino de dois jardins de infância no Alentejo e respectivas mães, situando-se um numa zona rural e o outro numa zona urbana do Alentejo. As respostas dos participantes a dois guias de entrevista semiestruturada (um para as crianças e o outro para as mães) foram analisadas com base na Consensual Qualitative Research. Os resultados revelam que as crianças percecionam a escola como espaço de aprendizagem e de relação com o outro, enquanto o trabalho é percebido como tendo a função de permitir apoio económico, produzir e adquirir bens. As crianças de meio rural consideraram mais do que as de meio urbano a escola como espaço de socialização. A perceção das mães sobre a escola e o trabalho surge na linha da dos filhos, sugerindo a influência da família neste tipo de representações. Os resultados são discutidos quanto às suas limitações e implicações para a prática do desenvolvimento vocacional na infância.

Palavras-chave: Escola, Trabalho, Desenvolvimento de Carreira, Família

\begin{abstract}
This study analyses the perception of school and work in kindergarten children and their mothers. Differences between urban and rural participants were also studied. The sample included 23 children (3 to 6 years old), 12 girls and 11 boys and their mothers, attending public kindergarten in rural and urban areas of Alentejo. Participants' answers to a semistructured interview script (one for the children and another for the mothers) were analyzed according to the Consensual Qualitative Research approach. Results reveal that children perceive school as a place of learning and socializing, while work is perceived as a means to both obtain economic support, and to produce and acquire goods. The perception of school as a place for socialization is significantly more frequent among rural children than among urban ones. Mothers' perception of school and work is similar to their children's perception. This result suggests family influence on the way children perceive school and work. Results are discussed considering their limitations and practical implications.
\end{abstract}

Keywords: School, Work, Career Development, Family

\section{INTRODUÇÃO}

É na família que, desde os primeiros anos de vida, as crianças começam a estruturar as suas primeiras impressões sobre a escola e o mundo do trabalho. Nesse sentido, o jogo simbólico, a observação e imitação do comportamento das pessoas que lhe são significativas, bem como as experiências de tipificação sexual, são relevantes (Gottfredson, 2002, 2005; Pinto \& Soares, 2001, 2002; Super, 1980; Taveira, 1999). 
Em Portugal, até à data, não estão publicados estudos que explorem as conceções de trabalho e de escola em crianças na educação pré-escolar ou no primeiro ciclo do ensino básico. Sendo estes dois conceitos centrais para as intervenções de desenvolvimento vocacional na infância (Herr \& Cramer, 2004; Taveira, 1999), o presente estudo analisa a perceção da escola e do trabalho em crianças de jardim de infância e nas suas mães. Deste modo, procuramos contribuir para fundamentar tais práticas.

\section{O desenvolvimento das conceções de trabalho na infância}

O interesse pelo estudo do desenvolvimento vocacional na infância está muito relacionado com a emergência das perspetivas desenvolvimentistas. Estas abordagens consideram o desenvolvimento vocacional como processo ao longo do ciclo de vida e integrado no desenvolvimento psicossocial. Nesta perspectiva, é na infância que se desenvolvem conceções da escola, do trabalho e das profissões, influentes do desenvolvimento vocacional na adolescência. A Teoria Ciclo de Vida / Espaço de Vida (Super, 1980), a de Circunscrição e Compromisso (Gottfredson, 2002, 2005) e o Modelo de Desenvolvimento sobre Conceções da Escolha de Carreira (Howard \& Walsh, 2011) são as que, de modo mais completo e complementar, conceptualizaram como se desenvolvem as conceções de trabalho e das profissões na infância.

$\mathrm{Na}$ Teoria Ciclo de Vida / Espaço de Vida concebem-se cinco estádios de desenvolvimento vocacional no ciclo de vida, caracterizados por tarefas de desenvolvimento muito próprias. Na infância, a fase de Crescimento é marcada pelo desenvolvimento do autoconceito vocacional. Inicialmente (4-5 anos), há um período de fantasia em que a criança não tem em consideração nem os fatores internos nem os externos na definição das suas aspirações. Gradualmente, vai desenvolvendo representações das suas necessidades, interesses (7-10 anos) e capacidades (1014 anos), o que lhe permite reelaborar aspirações fantasistas (e.g., ser cowboy, ser super-herói) para aspirações assentes em representações do seu potencial de realização e de si como trabalhador (Super, 1980; Taveira, 1999).

Na fase de Crescimento, as tarefas de desenvolvimento são: (a) começar a preocupar-se com o futuro; (b) aumentar o controlo sobre a sua própria vida; (c) motivar-se a vencer na escola e no trabalho; (d) adquirir hábitos e atitudes adequadas face ao trabalho (Super, Savickas \& Super, 1996). Para explicar como os indivíduos lidam com as tarefas de desenvolvimento, Super (1974) desenvolveu o conceito de maturidade vocacional, definida como a prontidão do indivíduo para lidar eficazmente com as tarefas/desafios da fase de desenvolvimento em que se encontra. É na fase de crescimento que emergem os fundamentos da maturidade vocacional, nomeadamente, atitudes favoráveis ao planeamento, exploração e tomada de decisão. O processo origina-se na curiosidade natural das crianças para explorarem o mundo que as rodeia. O reforço interno e externo do comportamento exploratório conduz a mais comportamento exploratório e mais informação. Por sua vez, a punição do comportamento exploratório leva ao conflito. Em todo este processo a família assume um papel relevante no modo como reforça a atividade exploratória inicial, favorecendo o conhecimento do contexto bem como a emergência de sentimentos de autonomia e confiança fundamentais para o indivíduo gerir as tarefas de desenvolvimento que se vão colocando ao longo do ciclo de vida (Super, 1990). 
A Teoria de Circunscrição e Compromisso (Gottfredson, 2002, 2005) é complementar à de Super por acentuar as dimensões sociais do desenvolvimento vocacional na infância. Considera-se que, desde cedo, as crianças interiorizam representações de papel sexual e de estatuto social que são marcantes das suas aspirações e decisões futuras. Assim, pelos 3-5 anos de idade ocorre o que se designa por fase de Orientação para a Forma e o Poder, pois o facto de as crianças terem adquirido a noção de constância do objecto permite-lhes classificar as pessoas de forma simples (e.g. grande vs. pequeno, poderoso vs. fraco). Nesta fase, as crianças também são capazes de reconhecer as profissões em termos de papéis do adulto, isto é, que há um mundo dos adultos do qual faz parte trabalhar num emprego.

Na fase seguinte, de Orientação para os Papéis Sexuais (6-8 anos), o pensamento concreto já permite fazer distinções simples, como entre "bom" e "mau". As influências culturais, associadas à capacidade de estabelecer dicotomias, favorecem o processo de tipificação sexual. No domínio vocacional, a consequência é que as crianças circunscrevem as suas aspirações às profissões típicas de pessoas do seu sexo. Assim, esta teoria dá um importante contributo para explicar porque os homens e as mulheres tendem a escolher profissões típicas do seu sexo (Gottfredson, 2005; Wood \& Kasubowski, 2008).

O Modelo de Desenvolvimento sobre Conceções da Escolha de Carreira (Howard \& Walsh, 2011) fundamenta-se em teorização sobre o desenvolvimento cognitivo para explicar os determinantes das escolhas vocacionais na infância. Define seis níveis de raciocínio sobre as escolhas vocacionais e sua concretização: (a) Associação Pura, (b) Pensamento Mágico, (c) Atividades Externas, (d) Processos Internos e Capacidades, (e) Interação e (f) Interação Sistémica. O desenvolvimento destas formas de raciocínio traduz-se na evolução de um foco em atividades e objetos externos às profissões, para depois já considerarem os passos a ter em conta na escolha e entrada num emprego e, finalmente, terem em conta os múltiplos factores envolvidos nas escolhas e no prosseguimento de uma profissão (Howard \& Walsh, 2011).

Em síntese, a teoria e a investigação sobre o desenvolvimento vocacional na infância sugerem o papel da família na construção de crenças e valores relativamente à escola e ao mundo do trabalho, influentes no planeamento, na exploração e na tomada de decisão vocacional, bem como nos sentimentos de agência pessoal.

\section{A família e o desenvolvimento vocacional na infância}

Uma importante área de estudo sobre o papel da família no desenvolvimento vocacional é a investigação no âmbito dos processos de vinculação. Os resultados evidenciam que indivíduos com padrão de vinculação seguro tendem a ser capazes de autoexploração e de exploração dos contextos em que vivem, são mais eficazes na tomada de decisão e na implementação dos planos de carreira, têm sentimentos de satisfação e ajustamento às atividades que realizam e evidenciam, ainda, relações mais adaptativas nos contextos de trabalho (Blustein, 2006; Blustein, Prezioso \& Schulteiss, 1995). No mesmo sentido, a investigação também tem mostrado que um ambiente familiar estimulante, que inclui envolvimento intelectual, comportamental e afetivo por parte dos pais, também contribui significativamente para mais consciência de si e do mundo em geral (Bryant, Zvonkovic \& Reynolds, 2006). Nesta linha de estudos, Koumoundourou, Tsaousis e Kounnenou (2011) verificaram, em adolescentes gregos, que a falta 
de coesão familiar e o estilo parental autoritário ou permissivo eram preditores de dificuldades de decisão de carreira, efeito que era mediado por autoavaliações nucleares.

Muitas vezes, é na brincadeira, no jogo do faz-de-conta, na observação e na aprendizagem por imitação do comportamento das pessoas significativas que a criança elabora as primeiras representações do trabalho, adquire o conhecimento referente às diferentes áreas profissionais, elabora as primeiras aspirações face à carreira e as primeiras crenças de autoeficácia face ao trabalho (Araújo \& Taveira, 2008; Araújo, Taveira \& Lemos, 2004; Bryant, Zvonkovic \& Reynolds, 2006). A influência da família no desenvolvimento vocacional das crianças também se faz sentir através da comunicação de motivações e aspirações que a criança interioriza (Bryant, Zvonkovic \& Reynolds, 2006; Faria, Taveira \& Pinto, 2008; Pinto \& Soares, 2002; Watson \& McMahon, 2007).

Tendo em conta o processo de construção das primeiras conceções de trabalho, e que a escola e a família são espaços influentes do desenvolvimento vocacional, a presente investigação, de natureza exploratória, procura responder à seguinte questão: que perceção têm da escola e do trabalho crianças em idade pré-escolar e os seus pais? De modo a aprofundar o conhecimento sobre as especificidades do desenvolvimento vocacional no que respeita às suas conceções de escola e de trabalho, também analisámos as diferenças quanto à proveniência urbana ou rural dos participantes. Tanto quanto conhecemos, até à data não há estudos nacionais e internacionais que analisem este tipo de diferenças relativamente às conceções de escola e de trabalho. Também justifica este tipo de análise o facto de em Portugal as regiões do Alentejo, Centro e Madeira serem as que apresentam mais baixas qualificações e maiores índices de abandono escolar (Conselho Nacional de Educação, 2014). Por outro lado, as zonas rurais, relativamente às urbanas, estão cada vez mais desertificadas e com menores oportunidades de emprego, como expressam os movimentos migratórios para as cidades e o estrangeiro. Ao abordarmos o conhecimento das especificidades do desenvolvimento vocacional, considerando o contexto urbano ou rural dos participantes, procuramos fundamentar intervenções que considerem as especificidades destas populações.

\section{MÉTODO}

\section{Participantes}

Entrevistaram-se 23 crianças e as respectivas mães. A primeira subamostra era constituída por 12 crianças do sexo feminino e 11 do sexo masculino, com idades compreendidas entre os três e os seis anos de idade $(M=4.91 ; D P=$ 0.85). Dez frequentavam um jardim de infância público, no perímetro urbano da cidade de Évora, e as restantes 13 um jardim de infância público em zona rural do distrito de Portalegre. A segunda subamostra foi constituída pelas 23 mães das crianças entrevistadas, cuja idade média era de 34 anos $(D P=5.64)$.

\section{Instrumentos}

Nesta investigação usaram-se dois guias de entrevista semiestruturada, mais especificamente um guia de entrevista para crianças e guia de entrevista para mães. 
Guia de entrevista para crianças - avalia, a partir de cinco questões, as preferências vocacionais das crianças e a perceção que têm da escola e do trabalho: "O que é que queres ser quando fores grande?", "Porque é que tu gostarias de ser...?", "Porque é importante as pessoas irem à escola?", "Porque é importante as pessoas trabalharem?", "Porque é que os teus pais querem que tu vás à escola?", "Os teus pais já falaram contigo sobre isso?"

Guia de entrevista para as mães - avalia o valor atribuído às aprendizagens escolares e ao trabalho, a perceção dos pais sobre a escola, sobre o trabalho e sobre os planos dos seus filhos. Este guião é composto pelas seguintes questões: "Em que é que foi importante para si a escola?", "Qual a importância do trabalho para si?", "Em que é que considera ser importante a escola para o(a) seu (sua) filho(a)?", "Habitualmente fala com o(a) seu (sua) filho(a) sobre estas questões?", "O que lhe diz?"

Os dois instrumentos foram construídos a partir da revisão de literatura (Araújo, 2004; Araújo \& Taveira, 2008; Araújo, Taveira, \& Lemos, 2004; Pinto \& Soares, 2001, 2002; Taveira, 1999) e, posteriormente, testados para avaliar a sua validade facial.

\section{Procedimento}

Para realizar as entrevistas obteve-se consentimento da Direção Geral de Inovação e Desenvolvimento Curricular e da Direção dos Agrupamentos de Escolas frequentados pelos participantes. Depois, agendaram-se as entrevistas às crianças e às mães, que decorreram no jardim de infância frequentado pelas crianças. Foram gravadas e, posteriormente, transcritas. Ao longo de todo o processo, foram assegurados os direitos éticos e deontológicos que assistem aos participantes.

\section{Investigadores}

Ambos os investigadores participaram na análise de dados, sendo a primeira investigadora do sexo feminino, psicóloga em várias Equipas Locais de Intervenção e tendo o segundo investigador, do sexo masculino, experiência em investigação qualitativa. Ambos possuem experiência e interesse no desenvolvimento infantil, em geral, e na psicologia vocacional, em particular. Numa fase prévia à recolha de dados, os investigadores refletiram em conjunto sobre as suas expectativas relativamente aos resultados do estudo. Deste modo, procuraram identificar fontes de enviesamento na análise dos dados e, consequentemente, maximizar a precisão dessa análise.

\section{Análise dos dados}

Os dois investigadores fizeram análise de conteúdo às respostas dos participantes. Consideraram como unidade de registo a ideia principal contida num determinado segmento de transcrição da entrevista em análise. Depois de definidas as unidades de análise, a primeira investigadora definiu os domínios, tendo como referência as questões da entrevista e a revisão de literatura. Depois, definiu categorias e subcategorias a partir da análise das respostas às entrevistas. De modo a reduzir a subjetividade da análise e, consequentemente, enviesamentos na definição das categorias, procurou-se que tivessem designações próximas da linguagem usada pelos participantes. De cinco em 
cinco entrevistas analisadas pela primeira investigadora, o segundo investigador auditava as mesmas. Estas só estavam concluídas quando ambos chegavam a consenso. $\mathrm{O}$ processo foi interativo até às últimas quatro entrevistas. Estas tinham sido aleatoriamente colocadas à parte de modo a testar a saturação dos dados. Este objectivo foi conseguido uma vez que as quatro entrevistas analisadas em separado não introduziram novas categorias ou domínios.

\section{RESULTADOS}

A frequência de resposta às entrevistas foi organizada de acordo com a sugestão de Hill e colaboradores (2005) para calcular rácios de resposta dos participantes em cada categoria. Assim, as categorias têm frequência de resposta Geral quando são referidas por todos os participantes, Típica quando referidas por mais de metade dos participantes, Variável quando mencionadas por menos de metade mas por mais do que dois participantes e Rara quando dois ou menos participantes a referem. Pela sua relevância, apenas as respostas Gerais e Típicas são discutidas.

Seguindo os critérios de Hill e colaboradores (2005), para avaliar se uma diferença de resultados é significativa considerou-se como critério a existência de dois níveis de diferença entre as frequências da mesma categoria, nas subamostras de residentes em meio urbano ou rural. Por exemplo, uma diferença é significativa se a frequência for rara numa subamostra e típica na outra subamostra.

\section{A perceção das crianças sobre a escola e o trabalho}

O Quadro 1, referente à perceção das crianças sobre a escola e o trabalho, apresenta, para cada questão, os domínios e categorias em que as respostas das crianças se organizaram. Emergiram três grandes domínios de respostas: (a) perceções de escola, (b) perceções de trabalho e (c) aspirações escolares e profissionais.

Quadro 1

Domínios, categorias e frequências referentes à perceção das crianças sobre a escola e o trabalho

\begin{tabular}{|c|c|c|c|c|}
\hline Domínios & Categorias & $\begin{array}{c}\text { Total } \\
n=23 \\
\text { Frequência }\end{array}$ & $\begin{array}{c}\quad \begin{array}{c}\text { Rural } \\
n=13 \\
\text { Frequência }\end{array}\end{array}$ & $\begin{array}{c}\text { Urbano } \\
n=10 \\
\text { Frequência }\end{array}$ \\
\hline Razões para ir à escola & $\begin{array}{l}\text { Aprender } \\
\text { Socializar }\end{array}$ & $\begin{array}{l}\text { Variável } \\
\text { Variável }\end{array}$ & $\begin{array}{l}\text { Variável } \\
\text { Típica }\end{array}$ & $\begin{array}{l}\text { Típica } \\
\text { Rara }\end{array}$ \\
\hline Razões dos pais para levar à escola & Aprender & Típica & Típica & Variável \\
\hline Razões para trabalhar & $\begin{array}{c}\text { Apoio económico } \\
\text { Produzir e } \\
\text { adquirir bens }\end{array}$ & $\begin{array}{l}\text { Típica } \\
\text { Típica }\end{array}$ & $\begin{array}{l}\text { Típica } \\
\text { Típica }\end{array}$ & $\begin{array}{c}\text { Típica } \\
\text { Variável }\end{array}$ \\
\hline Projetos vocacionais & $\begin{array}{c}\text { Fantasistas } \\
\text { Não fantasistas }\end{array}$ & $\begin{array}{l}\text { Variável } \\
\text { Típica }\end{array}$ & $\begin{array}{l}\text { Variável } \\
\text { Típica }\end{array}$ & $\begin{array}{l}\text { Variável } \\
\text { Típica }\end{array}$ \\
\hline
\end{tabular}

Para as crianças, vai-se à escola para aprender, razão que também atribuem aos pais para os levarem à escola. É 
ilustrativa a resposta de um dos participantes: Porque é importante para fazer os trabalhos, que é para aprender (7C, RUR).

Relativamente à perceção sobre o trabalho, os resultados evidenciam que as crianças referem com frequência típica que as pessoas trabalham para ter retorno económico e para produzir bens. Evidencia-o a seguinte resposta: Porque senão assim não existiam televisões e não viam reportagens nem coisas para adultos! (21C, URB).

Quanto às aspirações escolares e profissionais, os resultados evidenciam que a maioria dos participantes refere projetos não fantasistas. Um exemplo de projeto fantasista é o da seguinte resposta: Quando for grande quero ser um cão! (...) Porque os cães correm mais depressa e os meninos não conseguem apanhar os cães (4C, RUR). Por sua vez, é exemplo de projeto não fantasista: Doutora dos animais! Porque eu curava-os e ficavam bons (9C, RUR).

Entre as crianças de meio rural e de meio urbano só se verificaram diferenças significativas de resultados no domínio "Razões para ir à escola", na categoria "Permite socializar". Neste caso, os participantes de meio urbano consideraram com frequência rara que a razão de ir à escola era a socialização, enquanto os de meio rural o referiram com frequência típica.

\section{A perceção das mães sobre a escola e o trabalho}

O Quadro 2, referente à perceção das mães sobre a escola e o trabalho, apresenta, para cada questão, os domínios, categorias e subcategorias em que as respostas das mães se organizaram. Como se pode verificar, emergiram dois grandes domínios de respostas, o primeiro relativo às percepções sobre a escola e o segundo relativo às percepções sobre o trabalho.

Os resultados evidenciam que as mães consideram, com frequência típica, que a escola foi importante para construírem as bases para a aprendizagem académica e para o bom relacionamento com os outros. No mesmo sentido, consideram, de modo típico, que a escola é importante para a aprendizagem dos filhos e para o seu desenvolvimento psicossocial. É ilustrativa a resposta de uma das participantes:

(...) fundamental como preparação, como hábito de regras, de aprender a trabalhar...a cooperar (...). Além daquilo que nos passam em termos de conteúdos formais (...) aprender a lidar com os outros, a respeitar, a ter regras, a partilhar, tudo isso e a amizade que se cria com muita gente (22M, URB).

Quando as mães comunicam com os seus filhos sobre a escola, procuram, fundamentalmente, transmitir-lhes o valor da mesma para o futuro vocacional. São ilustrativas as palavras de uma das participantes onde a importância da escola para o futuro vocacional resulta do valor da escola para aprender:

Costumo-lhe dizer que tem que vir para a escolinha para aprender para, depois, quando for grande, ter uma profissão (16M, URB). 
No domínio "Importância do trabalho" as mães referem, de modo típico, que o trabalho é importante na sua vida para satisfazer necessidades de segurança económica (e.g. Hoje em dia quem não trabalha não se sustenta, 6M, RUR) e para permitir a utilização das capacidades (e.g. Portanto, o trabalho é o culminar de todo o esforço, não é?, 10M, RUR).

Quadro 2

Domínios, categorias e frequências referentes à perceção das mães sobre a escola e o trabalho

\begin{tabular}{|c|c|c|c|c|}
\hline Domínios & Categorias & $\begin{array}{l}\text { Total } \\
\quad n=23 \\
\text { Frequência }\end{array}$ & $\begin{array}{c}\text { Rural } \\
n=13 \\
\text { Frequência }\end{array}$ & $\begin{array}{l}\text { Urbano } \\
n=10 \\
\text { Frequência }\end{array}$ \\
\hline \multirow[t]{4}{*}{ Importância da escola } & $\begin{array}{l}\text { Muito importante } \\
\text { frequentar a escola }\end{array}$ & Variável & Variável & Típica \\
\hline & Aprender & Típica & Variável & Típica \\
\hline & Socializar & Típica & Típica & Variável \\
\hline & Desenvolvimento pessoal & Variável & Variável & Típica \\
\hline Importância dada à & Aprender & Típica & Típica & Típica \\
\hline escolarização dos filhos & Desenvolvimento global & Típica & Variável & Típica \\
\hline Comunicação sobre a escola & $\begin{array}{l}\text { Transmitir o valor da } \\
\text { escola }\end{array}$ & Típica & Típica & Variável \\
\hline \multirow[t]{3}{*}{ Importância do trabalho } & $\begin{array}{c}\text { É muito importante } \\
\text { trabalhar }\end{array}$ & Típica & Variável & Típica \\
\hline & Segurança económica & Típica & Típica & Típica \\
\hline & Utilização das capacidades & Típica & Variável & Típica \\
\hline \multirow[t]{2}{*}{$\begin{array}{c}\text { Comunicação sobre o } \\
\text { trabalho }\end{array}$} & $\begin{array}{l}\text { Transmitir o valor do } \\
\text { trabalho }\end{array}$ & Variável & Rara & Típica \\
\hline & $\begin{array}{c}\text { Promover o } \\
\text { desenvolvimento de } \\
\text { carreira }\end{array}$ & Variável & Rara & Típica \\
\hline
\end{tabular}

Finalmente, no domínio "Comunicação das mães sobre o trabalho", os resultados evidenciam que com frequência variável as mães procuram transmitir o valor do trabalho e promover o desenvolvimento de carreira, com frequência variável. Para promover o desenvolvimento de carreira falam de projetos vocacionais, como é ilustrativa a resposta de uma das participantes:

Tento sempre arranjar um bocadinho para estar com ela, para falarmos de projetos, às vezes sonhamos um bocadinho (...) «Mãe eu quero ser bailarina, mãe eu quero ser enfermeira!» (22M, URB).

Também dão a conhecer as várias profissões através da consulta de livros infantis (e. g. Já abordamos alguns livros, lá está, que falam sobre as profissões, para ele perceber um pouco as profissões, 17M, URB) ou pelo contacto com a sua realidade profissional (e.g. Ela está habituada ao trabalho da mãe, vai sempre ao trabalho da mãe. Eu agora estou no ginásio e ela gosta de ir para lá, 19M, URB).

Tal como na subamostra de crianças também na subamostra das mães não existem muitas diferenças de resultados em função da proveniência rural ou urbana. De facto, só se verificaram diferenças significativas para as duas 
categorias do domínio "Comunicação das mães sobre o trabalho". Neste domínio, as mães de meio rural só raramente transmitem o valor da escola e promovem o desenvolvimento de carreira dos filhos, enquanto as mães de meio urbano o fazem com frequência típica.

\section{DISCUSSÃO}

O objetivo deste estudo foi analisar a perceção da escola e do trabalho em crianças de jardim de infância e suas mães. A fim de aprofundar o entendimento da relação entre o contexto dos participantes e a sua perceção da escola e do trabalho, também se consideraram diferenças de resultados em função da sua proveniência urbana ou rural.

Os resultados obtidos evidenciam que as crianças percecionam a escola como espaço de aprendizagem e de relação com o outro. Este resultado pode explicar-se pela conotação atribuída à escola como lugar de aprendizagem académica, onde a instrução estruturada e dirigida pode contribuir para que os participantes tenham uma representação dessas aprendizagens como diferentes das realizadas noutros contextos. Por outro lado, a saliência dada à escola enquanto espaço de socialização pode justificar-se pela saliência das atividades lúdicas no currículo e nas dinâmicas educativas do jardim de infância. O resultado pode contribuir para explicar porque, futuramente, na fase de exploração da carreira (Super, 1990), os papéis de tempos livres e de estudante são os mais salientes na carreira dos jovens (Sverko \& Super, 1995).

Relativamente à perceção do trabalho, as crianças consideram que as principais funções do mesmo são permitir apoio económico, produzir e adquirir bens. Estes resultados vão ao encontro dos obtidos noutros estudos com adolescentes (Chaves et al., 2004), com portadores de deficiência mental (Cinamon \& Gifsh, 2004; Ferrari, Nota \& Soresi, 2008) e com adultos (Bowe, Bowe, \& Streeter, 2000), sugerindo que a centralidade desta função do trabalho começa a estruturar-se nos primeiros anos de vida. De facto, neste estudo, a perceção das mães sobre a escola e o trabalho surge na linha da perceção dos seus filhos. Para as mães, a importância do trabalho resulta de possibilitar segurança económica e a utilização das capacidades pessoais.

As mães que participaram no estudo consideraram que no nível da educação pré-escolar é muito cedo para abordar questões referentes ao desenvolvimento vocacional, em geral, e ao mundo do trabalho, em particular. O resultado é consonante com o obtido por Jacobs, Chandler e Hausknecht (1996) num estudo onde os pais referiam que os seus filhos em idade pré-escolar ainda eram muito jovens para compreender e conhecer o mundo do trabalho. Na presente investigação, o posicionamento das mães relativamente a considerarem ser cedo para estimular a exploração na carreira é, aparentemente contraditório com o facto de, com frequência variável, comunicarem o valor do trabalho e promoverem comportamentos de exploração vocacional. Possivelmente, uma concepção tradicional da intervenção vocacional como prática que só acontece nos momentos de tomada de decisão vocacional (Gysbers, Heppner \& Johnston, 2009; Whitaker, Philipps \& Tokar, 2004) pode justificar a contradição.

Nas crianças, a presença de projectos vocacionais fantasistas ou relativos a atividades profissionais de adultos próximos (e.g. médico, professor, educador de infância e polícia) é uma das expressões do momento de desenvolvimento em que os participantes se encontram. Em idade pré-escolar, as crianças vão reconhecendo que 
as profissões são papéis dos adultos, mas não têm conceções estáveis dos papéis sexuais ou conceções abstratas de masculino e feminino (Gottfredson, 2002). O seu pensamento evolui de um pensamento mágico para um pensamento intuitivo, e o foco é em atividades e objetos externos às profissões. Este conjunto de caraterísticas leva que os planos vocacionais expressem essa subjetividade e, por isso, já não sejam tão fantasistas e sejam, cada vez mais, influenciados pela realidade próxima e familiar (Araújo \& Taveira, 2008; Gottfredson, 2005; Howard \& Walsh, 2011; Super, 1990).

Tendo em conta a proveniência rural ou urbana dos participantes, foram poucas as diferenças significativas. As crianças de meio rural consideraram, mais do que as de meio urbano, a escola como espaço de socialização. Este resultado pode explicar-se pela crescente desertificação das zonas rurais, resultante da baixa natalidade e da crescente imigração, com consequências na redução do número de crianças disponíveis para brincar fora da escola.

Os resultados também evidenciaram que as mães de meio rural raramente comunicam com os filhos sobre o valor do trabalho e raramente estimulam a exploração de carreira, ao contrário das de meio urbano, que o fazem com frequência típica. Possivelmente, o meio urbano, por se caraterizar por maior competitividade escolar e profissional do que o meio rural (Van Esbroeck, 2008), pode levar à necessidade de, desde muito cedo, preparar as crianças para essa competitividade através de diálogo que vise, entre outros comportamentos, o de exploração de carreira.

\section{Limitações do estudo e implicações para a investigação}

Os resultados deste estudo devem ser contextualizados no quadro das limitações que o envolvem. A principal prende-se com o facto de não haver nenhum pai na amostra, pois só as mães se disponibilizaram a participar. O facto de os pais delegarem nas mães a participação no estudo pode expressar diferenças no acompanhamento escolar dos filhos e, consequentemente, no significado atribuído à escola e ao trabalho. Assim, é possível que as respostas desta subamostra tenham o viés do olhar feminino sobre o problema. A segunda limitação, a dimensão da amostra não permitir generalização dos resultados, resulta da natureza da investigação, mais interessada no entendimento aprofundado do fenómeno em estudo (Patton, 2002).

Destas limitações decorre a necessidade de futuras investigações implicarem maior dimensão e heterogeneidade da amostra dos pais, de modo a conseguir-se um entendimento mais completo da temática em causa. Na continuidade deste estudo, também seria vantajoso explorar com maior profundidade o processo pelo qual os familiares constroem as representações da escola e do trabalho nestas crianças. O conhecimento decorrente daria indicadores para intervenções com pais, no sentido de os envolver no futuro desenvolvimento vocacional e académico dos seus filhos.

\section{Implicações práticas}

Os resultados, ao revelarem que desde cedo as crianças têm conceções da escola e do trabalho, apoiam a tendência crescente, em escolas portuguesas, para a promoção do desenvolvimento de competências vocacionais desde os 
primeiros anos de escolaridade (Lopes, 2004). Esta tendência está em acordo com recente investigação evidenciando a importância de intervenções de desenvolvimento vocacional na infância para a promoção do sucesso académico, desenvolvimento da identidade pessoal e a ligação ao contexto social (Perry \& Wallace, 2015). A evidência obtida de que o diálogo sobre a escola e o trabalho é significativamente maior nas mães de meio urbano do que nas de meio rural também aponta a relevância deste tipo de intervenções em escolas e jardins de infância de meio rural. Tais práticas, se envolverem os pais, serão mais compreensivas e de valoroso contributo para a promoção da igualdade de oportunidades, em regiões onde as restrições de alternativas escolares e profissionais poderão potenciar o desinvestimento em planos de carreira mais ambiciosos. De modo a facilitar o envolvimento de docentes, encarregados de educação e psicólogos, será importante que haja infusão destas práticas no currículo escolar (Gomes, 2004). Este tipo de estratégia acrescentará, à vantagem referida, outra que tem a ver com o facilitar a conexão entre as atividades escolares e as de desenvolvimento vocacional (Watson \& McMahon, 2007), de que os trabalhos de Taveira (1999) e de Pinto e Magalhães (2004) são ilustrativos de boas práticas a implementar no $1^{\circ}$ ciclo do ensino básico.

\section{REFERÊNCIAS}

Ali, S. R., \& Menke, K. A. (2014). Rural Latino youth career development: An application of Social Cognitive Career Theory. The Career Development Quarterly, 62, 175-186.

Araújo, A. \& Taveira, M. C. (2008, May). A development-contextual approach to career development in childhood. Paper presented at the IVth Career Development Conference - Research and Teaching, Braga, Portugal.

Araújo, A., Taveira, M. C., \& Lemos, M. S. (2004). Uma experiência de intervenção precoce no desenvolvimento vocacional em contexto pré-escolar. In M.C. Taveira (Ed.), Desenvolvimento vocacional ao longo da vida: Fundamentos, princípios e orientações (pp. 197-209). Coimbra: Almedina.

Blustein, D. L. (2006). The psychology of working: A new perspective for career development, counseling, and public policy. Mahwah, NJ: Lawrence Erlbaum.

Blustein, D. L., Prezioso, M. S., \& Schulteiss, D. P. (1995). Attachment theory and career development: Current status and future directions. The Counseling Psychologist, 23, 416-432.

Blustein, D. L., Chaves, A. P., Diemer, M. A., Gallagher, L. A., Marshall,K. G., Sirin, S., \& Bhati, K. S. (2002). Voices of the forgotten half: The role of social class in the school-to-work transition. Journal of Counseling Psychology, 49, $311-323$.

Blustein, D. L., Juntunen, C. L., \& Worthington, R. L. (2000). The school-to-work transition: Adjustment challenges of the forgotten half. In S. D. Brown \& R. W. Lent (Eds.), Handbook of counseling psychology (3rd ed., pp. 435-470). New York: Wiley.

Bowe, J., Bowe, M., \& Streeter, S. (2000). Gig: Americans talk about their jobs. New York: Three Rivers.

Bryant, B. K., Zvonkovic, A. M., \& Reynolds, P. (2006). Parenting in relation to child and adolescent vocational development. Journal of Vocational Behavior, 69, 149-175.

Chaves, A. P., Diemer, M. A., Blustein, D. L., Gallagher, L. A., DeVoy, J. E., Casares, M. T., \& Perry, J. C. (2004). Conceptions of work: The view from urban youth. Journal of Counseling Psychology, 51, 275-286.

Cinamon, R. G., \& Gifsh, L. (2004). Conceptions of work among adolescents and young adults with mental retardation. The Career Development Quarterly, 52, 212-224. 
Conselho Nacional de Educação. (2014). Estado da educação 2012: Autonomia e descentralização. Lisboa: Autor.

Faria, L., Taveira M. C., \& Pinto, J. (2008). Processos de influência parental e carreira na adolescência. Revista Psicologia e Educação, 7, 109-126.

Ferrari, L., Nota, L., \& Soresi S. (2008). Conceptions of work in Italian adults with intellectual disability. Journal of Career Development, 20, 1-27.

Gottfredson, L. S. (2002). Gottfredson's theory of circumscription, compromise, and self-creation. In D. Brown (Ed.), Career choice and development (4th ed., pp. 85-148). San Francisco: Jossey-Bass.

Gottfredson, L. S. (2005). Applying Gottfredson's theory of circumscription and compromise in career guidance and counseling. In S. D. Brown \& R. W. Lent (Eds.), Career development and counseling: Putting theory and research to work (pp. 71-100). Hoboken, NJ: John Wiley \& Sons.

Gysbers, N. G., Heppner M. J., \& Johnston, J. A. (2009). Career counselling: Process, issues, and techniques (3rd ed.). Boston: Allyn and Bacon

Herr, E. L., \& Cramer, S. H., (2004). Career guidance and counseling through the lifespan: Systematic approaches (6th ed.). New York: Harper Collins.

Hill, C., Thompson, B. J., Hess, S. A., Knox, S., Williams, E. N., \& Ladany, N. (2005). Consensual Qualitative Research: An update. Journal of Counseling Psychology, 52, 196-205.

Howard, K. A. S., \& Walsh, M. E. (2011). Children's conceptions of career choice and attainment: Model development. Journal of Career Development, 38, 256-271.

Jacobs, N. L., Chandler, T. M., \& Hausknecht, D. R. (1996). Unraveling the mystery of parents' work. Early Childhood Education Journal, 24, 61-64.

Lopes, A. (2004). Desenvolvimento vocacional na infância e prevenção do abandono escolar: contributos dos serviços de psicologia e orientação. In M. C. Taveira (Ed.), Desenvolvimento vocacional ao longo da vida: Fundamentos, princípios e orientações (pp. 191-196). Coimbra: Almedina.

McMahon, M., \& Rixon, K. (2007). The career development of rural Queensland children. Australian Journal of Career Development, 16, 39-50.

Perry, J. C., \& Wallace, E. W. (2015). Children and adolescents. In P. J. Hartung, M. L. Savickas, \& W. B. Walsh (eds.) APA Handbook of career intervention (Vol.1, pp. 189-207). Washington, DC: American Psychological Association.

Pinto, H. R., \& Soares, M. C. (2001). Influência parental na carreira: Evolução de perspectivas na teoria, na investigação e na prática. Psychologica, 26, 135-149.

Pinto, H. R., \& Soares, M. C. (2002). Influência parental no desenvolvimento vocacional dos adolescentes. Revista Portuguesa de Psicologia, 36, 111-137.

Pinto, H. R., \& Magalhães, M. J. (2004). Construir o Futuro - programa “Quem Faz o Quê”. Lisboa: CEGOC-TEA.

Patton, M. Q. (2002). Qualitative research and evaluation methods (3rd ed.). Thousand Oaks, CA: Sage.

Super, D. E. (1974). Vocational maturity: Toward implementing a psychology of careers in career education and guidance. In D. E. Super (Ed.), Measuring vocational maturity for counseling and evaluation (pp. 9-23). Washington, DC: National Vocational Guidance Association.

Super, D. E. (1980). A life-span, life-space approach to career development. Journal of Vocational Behavior, 16, $282-298$.

Super, D. E. (1990). A life-span, life-space approach to career development. In D. Brown \& L. Brooks (Eds.), Career choice and development: Applying contemporary theories to practice (2nd ed., pp.197-261). San Francisco: Jossey-Bass.

Super, D. E., Savickas, M. L., \& Super, C. M. (1996). The life-span, life-space approach to careers. In D. Brown, \& L. Brooks (Eds.), Career choice and development (3rd ed., pp. 121-178). San Francisco: Jossey-Bass. 
Sverko, B., \& Super, D. E. (1995). The findings of the Work Importance Study. In D. E. Super \& B. Sverko (Eds.), Life roles, values, and careers: International findings of the Work Importance Study (pp. 349-358). San Francisco: JosseyBass.

Taveira, M. C. (1999). Intervenção precoce no desenvolvimento vocacional. Psicologia: Teoria, Investigação e Prática, 1, 173-190.

Koumoundourou, G., Tsaousis, I, \& Kounnenou, K. (2011). Parental influences on Greek adolescents' career decision-making difficulties: The mediating role of core self-evaluations. Journal of Career Assessment, 19, 165-182. doi: $10.1177 / 1069072710385547$

Van Esbroeck, R. (2008).Career guidance in a global world. In J.A. Athanasou \& R. Van Esbroeck (Eds.), International handbook of career guidance (pp. 23-44). Dordrecht, The Netherlands: Springer.

Watson, M., \& McMahon M. (2007). School and work: connections made by South African and Australian primary school children. South African Journal of Education, 27, 565-577.

Whitaker, L. A., Philipps, J. C., \& Tokar, D. M. (2004). Influencing client expectations about career counseling using a videotaped intervention. The Career Development Quarterly, 52, 309-322.

Wood, C., \& Kasubowski, J. (2008). The career development needs of rural elementary children. The Elementary School Journal, 108, 431-444. 